\title{
1 A Patient with Pontocerebellar Hypoplasia Type 6: Novel RARS2 Mutations, Comparison to \\ 2 Previously Published Patients and Clinical Distinction from PEHO Syndrome
}

3

4 Viivi Nevanlinna ${ }^{\mathrm{a}, \mathrm{b}}$, Svetlana Konovalova ${ }^{\mathrm{c}}$, Berten Ceulemans ${ }^{\mathrm{d}}$, Mikko Muona ${ }^{\mathrm{a}, 1}$, Anni Laari ${ }^{\mathrm{a}, \mathrm{c}}$, Taru

5 Hilander ${ }^{c}$, Katarin Gorski ${ }^{a, c}$, Leena Valanne ${ }^{e}$, Anna-Kaisa Anttonen ${ }^{a, f, g}$, Henna Tyynismaac, f, h,

6 Carolina Courage ${ }^{\mathrm{a}, \mathrm{c}}$, Anna-Elina Lehesjoki ${ }^{\mathrm{a}, \mathrm{c}, \mathrm{f},{ }^{*}}$

$8 \quad$ aFolkhälsan Research Center, Helsinki, Finland

$9 \quad$ bFaculty of Medicine and Life Sciences, University of Tampere, Tampere, Finland

10 'Research Programs Unit, Molecular Neurology, University of Helsinki, Finland

11 dDepartment of Pediatric Neurology, Antwerp University Hospital, University of Antwerp, Belgium

12 eDepartment of Radiology, Hospital District of Helsinki and Uusimaa Medical Imaging Center,

13 University of Helsinki and Helsinki University Hospital, Helsinki, Finland

14 fDepartment of Medical and Clinical Genetics, Medicum, University of Helsinki, Finland

15 sLaboratory of Genetics, Helsinki University Hospital, Helsinki, Finland

16 hNeuroscience Center, HiLIFE, University of Helsinki, Helsinki, Finland

17 1Present address: Blueprint Genetics, Helsinki, Finland

$18{ }^{*}$ Corresponding author. Folkhälsan Research Center, Biomedicum Helsinki, Haartmaninkatu 8,

19 00290, Helsinki, Finland; tel: +358 2941 25072; email: anna-elina.lehesjoki@helsinki.fi 


\section{Abstract}

21 Pontocerebellar hypoplasia type $6(\mathrm{PCH} 6)$ is a rare infantile-onset progressive encephalopathy 22 caused by biallelic mutations in RARS2 that encodes the mitochondrial arginine-tRNA synthetase 23 enzyme (mtArgRS). The clinical presentation overlaps that of PEHO syndrome (Progressive 24 Encephalopathy with oedema, Hypsarrhythmia and Optic atrophy). The proband presented with 25 severe intellectual disability, epilepsy with varying seizure types, optic atrophy, axial hypotonia, 26 acquired microcephaly, dysmorphic features and progressive cerebral and cerebellar atrophy and 27 delayed myelination on MRI. The presentation had resemblance to PEHO syndrome but 28 sequencing of ZNHIT3 did not identify pathogenic variants. Subsequent whole genome sequencing 29 revealed novel compound heterozygous variants in RARS2, a missense variant affecting a highly 30 conserved amino acid and a frameshift variant with consequent degradation of the transcript 31 resulting in decreased mtArgRS protein level confirming the diagnosis of PCH6. Features 32 distinguishing the proband's phenotype from PEHO syndrome were later appearance of hypotonia 33 and elevated lactate levels in blood and cerebrospinal fluid. On MRI the proband presented with 34 more severe supratentorial atrophy and lesser degree of abnormal myelination than PEHO 35 syndrome patients. The study highlights the challenges in clinical diagnosis of patients with 36 neonatal and early infantile encephalopathies with overlapping clinical features and brain MRI 37 findings.

\section{Keywords}

40 Pontocerebellar hypoplasia type 6, RARS2, PEHO syndrome, progressive cerebellar and cerebral

41 atrophy 
42

\section{Introduction}

43 Pontocerebellar hypoplasia $(\mathrm{PCH})$ is a group of neurodegenerative disorders with autosomal recessive inheritance. Up to date 11 different subtypes have been described, with 17 causative genes identified (van Dijk et al., 2018). Most of the subtypes are characterized by prenatal or neonatal onset, global developmental delay and intellectual disability, microcephaly, hypoplasia and variable atrophy of cerebellar cortex and/or brainstem. The specific neurological symptoms and the severity of symptoms and brain loss vary between the subtypes (van Dijk et al., 2018).

Pontocerebellar hypoplasia type 6 (PCH6; MIM 611523) is a rare form of PCH first described in 2007 in three patients of a consanguineous Sephardic Jewish family (Edvardson et al., 2007). Since then, altogether 32 patients in 18 families have been reported in the literature (for a detailed summary of the patients and phenotypes, see Supplementary Table; Edvardson et al., 2007; Rankin et al., 2010; Namavar et al., 2011; Glamuzina et al., 2012; Cassandrini et al., 2013; Kastrissianakis et al., 2013; Joseph et al., 2014; Li et al., 2015; Lax et al., 2015; Nishri et al., 2016; Alkhateeb et al., 2016; Ngoh et al., 2016; van Dijk et al., 2017; Luhl et al., 2016; Zhang et al., 2018). Most PCH6 patients present with neonatal onset, hypotonia, microcephaly, seizures, severe intellectual disability with lack of developmental milestones and progressive atrophy of cerebral cortex, cerebellum and pons. The majority show a respiratory chain enzyme deficiency and elevated lactate levels in blood or cerebrospinal fluid (CSF). Indeed, PCH6 may be distinguished from the other PCH subtypes, which are highly variable clinically and neuroradiologically, by the 61 presence of elevated lactate concentration (van Dijk et al., 2018). PCH6 is caused by biallelic mutations in RARS2, a nuclear gene that encodes the mitochondrial arginine-tRNA synthetase enzyme (mtArgRS) (Edvardson et al., 2007). Aminoacyl-tRNA synthetases play a crucial role in protein translation as they catalyze the specific attachment of an amino acid 
65 (aminoacylation) to its cognate tRNA. MtArgRS participates in the synthesis of all 13

mitochondrial-encoded proteins by charging of mitochondrial tRNA-Arg, thus being an integral part of mitochondrial protein translation machinery, participating in generation of complexes of oxidative phosphorylation system, except complex II, which has a fully nuclear origin (Ibba and Soll, 2000).

PCH6 shows clinically some resemblance to PEHO syndrome (Progressive Encephalopathy with oedema, Hypsarrhythmia and Optic atrophy; MIM 260565), characterized by neonatal hypotonia, profound psychomotor retardation, infantile spasms with hypsarrhythmia and atrophy of optic disks (Salonen et al., 1991). Patients present with typical dysmorphic features, such as narrow forehead, epicanthic folds, short nose and open mouth, and edema of the face and limbs (Somer, 1993). Neuroimaging findings include demyelination and progressive atrophy of the cerebellar cortex, brainstem and optic nerves. In the cerebellum, the inner granular layer is nearly totally absent and Purkinje cells are deformed and disaligned (Haltia and Somer, 1993).

PEHO syndrome is inherited autosomal recessively and was recently shown to be caused in Finnish patients by a homozygous missense mutation c.92C>T; p.Leu31Ser in ZNHIT3, a gene encoding zinc 80 finger HIT domain-containing protein 3 (Anttonen et al., 2017). PEHO syndrome is enriched in the Finnish population with an estimated incidence of 1:74 000 (Somer, 1993) and approximately 40 diagnosed patients. In other populations it is very rare, with less than 25 reported patients (Field et al., 2003; Caraballo et al., 2011; Alfadhel et al., 2011) and only one patient with compound 84 heterozygous mutations in ZNHIT3 reported so far (Öunap et al., 2019). In the literature, patients 85 with symptoms closely resembling PEHO syndrome are more commonly reported. The clinical presentation of patients with $\mathrm{PEHO}$-like features, like those with $\mathrm{PCH}$, is similar to that of $\mathrm{PEHO}$ syndrome, but optic atrophy and typical neuroradiologic findings are usually absent or there is no 
88 progression (Field et al., 2003; Longman et al., 2003; Chitty et al., 1996). Several genes underlying

94 genome sequencing revealed novel compound heterozygous mutations in RARS2.

phenotypes resembling PEHO have been described (Rankin et al., 2010; Anttonen et al., 2015;

Gawlinski et al., 2016; Langlois et al., 2016; Nahorski et al., 2016; Flex et al., 2016; Miyake et al.,

91 2016; Zollo et al., 2017; Chitre et al., 2018).

92 We report a patient with the initial presenting features suggestive of PEHO syndrome with typical

93 dysmorphic features, epileptic spasms, optic atrophy and severe hypotonia, but in whom whole 
Materials and methods

\section{Whole genome sequencing}

Library preparation for the genomic DNA sample was performed using KAPA Library Preparation Kit. The sample was sequenced in three lanes of an Illumina HiSeq2500 instrument with one lane having paired-end 250-bp reads and two lanes paired-end 10-bp reads. Sequence read alignment to human reference genome (GRCh37) and variant calling (Li et al., 2009) was done as described earlier with minor modifications (Sulonen et al., 2011). Called variants were annotated using ANNOVAR (Wang et al., 2010) and filtered using in-house scripts. DELLY (Rausch et al. 2012), which assesses split-read alignments and paired-end read information to detect structural variants was used to identify any copy number changes overlapping with the ZNHIT3 locus. Sanger sequencing 
was performed from genomic DNA of the patient and the parents to validate the variants

\section{Western blot analysis}

Protein extracts for the detection of mtArgRS, COXII or GAPDH were prepared by lysing fibroblasts in RIPA buffer (Cell Signaling Technology) containing protease inhibitors (Halt, Thermo Fisher Scientific). After $10 \mathrm{~min}$ incubation on ice the samples were centrifuged at $14000 \mathrm{~g}$ for $10 \mathrm{~min}(+4$ $\left.{ }^{\circ} \mathrm{C}\right)$. Proteins were separated by SDS-PAGE and transferred onto membranes. After blocking with $5 \%$ milk in $0.1 \%$ TBS-Tween 20 , the membranes were incubated with the corresponding primary antibodies: rabbit anti-human mtArgRS (1:1000, Biorbyt, orb374171), rabbit anti-human COXII (1:500, GeneTex, GTX62145) or rabbit anti-human GAPDH (Cell Signaling Technology, 14C10). Reactive bands were detected using horseradish peroxidase-conjugated secondary antibodies (goat anti-rabbit or goat anti-mouse, 1:10 000, Life Technologies). Blots were imaged using the ECL western blotting substrate (Thermo Fisher Scientific) and Chemidoc XRS+ Molecular Imager (BioRad). Quantification of the band intensities was performed with the Image Lab Software (Bio-Rad). 
Northern blot and aminoacylation assay

Total RNA was extracted from cultured fibroblasts using Trizol reagent (Thermo Fisher scientific) according to the manufacturer's instructions. To preserve the aminoacylation state the final RNA pellet was re-suspended in $10 \mathrm{mM} \mathrm{NaOAc}$ at $\mathrm{pH}$ 5.0. To investigate the aminoacylation status of mt-tRNAs, $4 \mu \mathrm{g}$ of RNA was separated on long (16cm length) $6.5 \%$ polyacrylamide gel $(19: 1$ acrylamide:bis-acrylamide) containing $8 \mathrm{M}$ urea in $0.1 \mathrm{NaOAc}, \mathrm{pH}$ 5.0. The fully deacylated tRNA (dAc) was obtained by incubation of the control RNA at $75^{\circ} \mathrm{C}(\mathrm{pH} 9.0)$ for $15 \mathrm{~min}$. To determine mttRNA ${ }^{\text {Arg }}$ steady-state levels the samples were run on $10 \mathrm{~cm}$ gel. Northern hybridization was performed with $\curlyvee$-32P labeled oligonucleotide probes: 5'-GAGTCGAAATCATTCGTTTTG-3' for the mt-tRNA ${ }^{\text {Arg }}$ and 5'- GTGGCTGATTTGCGTTCAGT-3' for the mt-tRNA ${ }^{\text {Ala }}$. Radioactive signal was 
Results

\section{Clinical description}

The essential clinical features in our patient are summarized in Supplementary Table. The patient was the first child of non-consanguineous Belgian parents. Family history was unremarkable. He was born at term after an uneventful pregnancy. Birth weight was $3.150 \mathrm{~kg}$ (-1 SD), length $50 \mathrm{~cm}$ ($1 \mathrm{SD})$ and head circumference $35 \mathrm{~cm}(-0.5 \mathrm{SD})$. After birth slight hypothermia occurred, leading to one day neonatal care, but otherwise physical examination was normal. Very early psychomotor milestones were reported normal, but at the age of 2 to 3 months lack of social interaction, late visual contact and mild hypotonia were noted. No further developmental milestones were reached, he had no speech and showed no real social contact. The patient had no dysmorphic signs at birth, but later presented with bitemporal narrowing, high palate, open mouth, full cheeks, a tented upper lip (Fig. 1A) as well as mild edema of hands (Fig. 1B) and feet. Eye examination showed no visual contact and a pale papilla on both eyes later progressing to optic atrophy. Due to feeding difficulties the child was tube fed. An acquired microcephaly was noted with occipitofrontal circumference (OFC) of $43 \mathrm{~cm}(-3.3 \mathrm{SD})$ at the age of 1 year and $46 \mathrm{~cm}(-3.7$ SD) at the age of 3 years. At the last clinical follow-up with 9 years of age, he presented as a bedridden child with profound intellectual disability, axial hypotonia, spastic quadriplegia and significant seizure burden.

First convulsions were witnessed at the age of 6 weeks with lateralized clonic movements of the face, followed by diminished consciousness and eye deviation to one side as well as bilateral clonic movements of the body. It is unclear from the history whether these seizures were already present from birth. Convulsions evolved into therapy-resistant epilepsy with varying seizure types: complex focal seizures (with and without diminished consciousness) with myoclonic jerks and laughing, rhythmic clonic movements of one or both limbs and long-lasting eye deviations with 
nystagmus. The patient suffered from daily seizures several times a day with isolated myoclonic spams and clusters in between.

EEG studies at the age of one to 3 months showed normal background activity without any epileptic activity. Multifocal epileptic activity was seen from the age of 4 months and high voltage slow background activity from the age of 5 months. The EEG did show some signs of hypsarrhythmia and could, because lack of total desynchronization, be described as a modified hypsarrhythmia. The last EEG recording, taken one day before the patient died, demonstrated a picture of status epilepticus with continuous multifocal epileptic activity.

Magnetic resonance imaging (MRI) was performed at the ages of 4.5 months and 7 years. At 4.5 months (Fig. 1C,D), it showed severe cerebral atrophy, destruction of the thalami, and delayed myelination, whereas the cerebellum appeared normal in size. At 7 years (Fig. 1E-G), the cerebellar atrophy was prominent, and microcephaly masked some of the cerebral atrophy. The pons was normal, and the myelination had reached almost a normal appearance.

Thorough metabolic investigations were unremarkable, with the exception of an intermittently raised serum lactate up to $5.3 \mathrm{mmol} / \mathrm{I}(0.5-2 \mathrm{mmol} / \mathrm{I})$ and an elevated lactate level in the CSF, up to $2.8 \mathrm{mmol} / \mathrm{l}(<2.5 \mathrm{mmol} / \mathrm{l})$. No abnormalities were seen in the muscle biopsy.

Prior genetic investigations including karyotype and microarray came out normal and mitochondrial DNA mutations were excluded.

The patient died at the age of nearly 12 years due to a respiratory infection.

\section{Molecular findings: RARS2 mutations and their consequence}

Given that the patient presented with symptoms overlapping with those reported in PEHO syndrome, his DNA was first Sanger sequenced to identify variants in the coding regions and splice 
sites of ZNHIT3. A rare heterozygous c.8C>T, p.Ser3Leu (NM_004773.3) missense variant was

identified, but the patient did not have other ZNHIT3 coding sequence variants. To identify any non-coding variants in ZNHIT3 locus, the patient was whole genome sequenced. Analysis for rare sequence variants in intronic or UTR regions of ZNHIT3, or up- or downstream to ZNHIT3 did not identify a second variant. No copy number changes overlapping with the ZNHIT3 locus was identified.

Analysis of the whole genome data was then expanded to all protein coding regions of the genome and splice sites. Whole genome sequence data was produced with mean sequencing coverage of $24.48 x$, and $98.2 \%, 95.7 \%$ and $74.2 \%$ of the genome was covered at least $5 x, 10 x$ and 20x, respectively. Analysis of the coding regions from the genome sequence data focused on rare heterozygous and potentially biallelic variants in established disease genes. Analysis of rare heterozygous variants did not yield any likely candidates explaining the patient's disease. Analysis of rare biallelic variants revealed two heterozygous variants in RARS2 (NM_020320.3; Fig. 2A and B; https://databases.lovd.nl/shared/individuals/00234052), a one-bp deletion in exon 10 causing a frameshift and premature termination of translation 16 codons downstream (c.795delA, p.Glu265Aspfs*16) and a missense variant, c.961C>T, p.Leu321Phe, in exon 11. There is one heterozygous carrier for the c.961C>T, p.Leu321Phe variant in the gnomAD (Lek et al., 2016) database (v. 2.0; allele frequency 0.000004), whereas the frameshift variant is absent from the database. The leucine at position 321, located in the catalytic domain of RARS2, is highly conserved (Fig. 2B). In silico tools SIFT, PolyPhen-2 and MutationTaster predict the c.961C>T, p.Leu321Phe substitution as deleterious. Sanger sequencing confirmed compound heterozygosity of the two mutations in the patient: the c.795delA frameshift mutation was inherited from the mother and the c.961C >T missense mutation from the father (Fig. 2A).

The consequence of the RARS2 variants was studied on mRNA level in skin fibroblasts of the 
${ }_{653}^{652} 225$ patient. The frameshift variant in exon 10 resulting in a premature termination codon is predicted

to be subjected to nonsense-mediated mRNA decay (NMD) and degradation of the transcript derived from the maternal allele. Indeed, sequencing of RARS2 cDNA revealed that at position C.961 only the paternal C>T variant was present (Fig. 2C). Western blot analysis of patient fibroblasts revealed that the mtArgRS protein level was reduced to about $50 \%$ of control level (Fig. 3A). Northern blot analysis of total RNA from fibroblasts suggested that the steady-state level of mitochondrial tRNA ${ }^{A r g}$ when compared to mitochondrial tRNA ${ }^{\text {Ala }}$ may be decreased in patient fibroblasts (Fig. 3B). In patient and control fibroblasts, aminoacylation analysis showed the presence of only aminoacylated mt-tRNA ${ }^{\text {Arg }}$, whereas deacylated mt-tRNA ${ }^{\text {Arg }}$ was not detected (Fig. 3C). This finding is in agreement with the previous observation (Edvardson et al., 2007), suggesting that in cultured human fibroblasts uncharged mt-tRNA ${ }^{\text {Arg }}$ is not stable. 


\section{Discussion}

We describe a patient compound heterozygous for two novel pathogenic variants in RARS2, the gene associated with PCH6. The high conservation of the affected Leu321, the predicted deleteriousness of the Leu321Phe substitution combined with degradation of the transcript derived from the allele with the frameshift variant strongly suggest that these variants are the underlying cause for $\mathrm{PCH} 6$ in the patient.

The role of RARS2 in pontocerebellar hypoplasia is not fully understood with no clear genotypephenotype correlations. It is though likely that the severity of the disease is dependent of the amount of remaining aminoacylation activity (Konovalova and Tyynismaa, 2013). mtArgRS has a fundamental function in mitochondrial protein synthesis, so total loss-of-function mutations are likely to be lethal. Compatible with this notion, mice homozygous for a knock-out allele of Rars2 are embryonic lethal (International Mouse Phenotyping Consortium;

http://www.mousephenotype.org/data/genes/MGI:1923596\#section-associations). Considering the markedly reduced expression from the frameshift allele, the missense mutant allele is likely to retain some mtArgRS activity in our patient. It has been suggested that due to the leaky nature of the mutations, small amounts of protein synthesis is possible in most tissues, but in high energy demanding cells, such as neurons, the reduced aminoacylation is not sufficient thus causing the symptoms of the disease (Edvardson et al., 2007). Low enzyme activity affects the development of the central nervous system already in utero as demonstrated by abnormal brain MRI findings in the neonatal period (e.g. Edvardson et al., 2007; Joseph et al., 2014; Lax et al., 2015). It is also possible that the reduced aminoacylation of tRNA-Arg has bigger effect on specific neuronal types that causes the alterations in brain typical for PCH6. There is also evidence of particular uncharged tRNAs and amino acids working as potential signaling molecules (Dong et al., 2000; Wolfson et al., 2016). Mitochondrial tRNA synthetases may also have non-canonical functions, similarly to their 
cytosolic counterparts, in addition to their housekeeping function in protein synthesis, and these

specific sub-mitochondrial localization in the membrane, which suggests that it also could have alternative functions (Gonzáles-Serrano et al., 2018). Regardless of the reason, this high tissue specificity makes functional studies of the disease mechanism challenging.

Including the present patient, 33 patients with PCH6 in 19 families have been described

(Supplementary Table). An overview of the key clinical features in the patients is presented in Table 1. Most patients were normal at birth but presented with variable symptoms at early age (hours to 9 months). First presenting features included hypotonia in 15/33 patients and seizures in 16/33 patients. Other early symptoms were poor feeding, lethargy and apneic episodes. All patients were reported to have global developmental delay and the majority presented seizures, the onset varying from 9 hours to several months. Most seizures were intractable myoclonic or tonic-clonic seizures, either focal, or multifocal or generalized. Other common features in the patients include progressive microcephaly, atrophy of cerebellum and cerebrum, as well as elevated lactate levels in blood or CSF. Notably, atrophy of pons was reported to be present in only 12 out of the 25 patients with reported MRI findings, indicating that pons can be normal in PCH6 (Nishri et al., 2016). The phenotype in our patient is similar to that of previously published patients, and presents with all features listed in Table 1, except atrophy of the pons. Of note, as in at least three published patients (Ngoh et al., 2016; Zhang et al., 2018; Luhl et al., 2016), the serum lactate levels in our patient were intermittently raised.

Compatible with a previous report (Rankin et al., 2010), the initial clinical features in our patient including severe intellectual disability, epilepsy, optic atrophy, hypotonia, acquired microcephaly, mild edema of hands and feet, and dysmorphic features pointed to PEHO syndrome. Although the dysmorphic features raised the suspicion of the PEHO syndrome, they may, however, be non- 
specific, as many of the dysmorphic facial features are associated with developing microcephaly,

extreme floppiness, and edema (Somer, 1993). Contrary to findings in our patient, patients with

PEHO syndrome do not show elevated lactate levels in blood or CSF and usually present with neonatal hypotonia (Anttonen et al., 2017). Importantly, the MRI findings in our patient (Fig. 1C-G) were not typical for PEHO syndrome. The supratentorial atrophy was more severe than in a typical PEHO patient. Moreover, the myelination was not delayed to the degree seen in PEHO patients. Characteristic MRI findings including progressive cerebellar atrophy and dysmyelination are essential diagnostic criteria for PEHO syndrome (Anttonen et al., 2017). These typical findings are often disregarded when suggesting a clinical PEHO diagnosis.

\section{Acknowledgements}

We thank the family for their contribution to this study. We thank the Genome Aggregation

Database (gnomAD) and the groups that provided exome and genome variant data to this resource. A full list of contributing groups can be found

at http://gnomad.broadinstitute.org/about. This study was funded by the Folkhälsan Research Foundation.

\section{Accession numbers}

https://databases.lovd.nl/shared/individuals/00234052 
Figure Titles and Legends

\section{Figure 1. Phenotypic features in the patient.}

A) Facial features of the patient at 7 years of age. Note the open mouth, full cheeks, a tented upper lip and bitemporal narrowing. B) The hand shows edema. C) In a sagittal T1-weighted cranial magnetic resonance image at the age of 4.5 months cerebellum (arrowhead) and pons (arrow) appear normal in size. D) T2-weighted axial image at 4.5 months shows cerebral atrophy.

E \& F) T2-weighted images of the patient at 7 years of age show microcephaly and widespread cerebral atrophy as well as severe cerebellar atrophy (arrowhead in E) with widened cerebellar sulci (F). The pons (arrow in $\mathbf{E}$ ) as well as the myelination appear normal. G) T2-axial slices at 7 years also show atrophy and signal increase of the thalami (open arrowheads).

Figure 2. Two novel PCH6-associated mutations in the RARS2 gene.

A) Sanger sequencing chromatograms of the proband's $(P)$ and the parents' genomic DNA showing the c.795delA variant inherited from the mother $(\mathrm{M})$ and the $\mathrm{c.961C}>\mathrm{T}$ variant inherited from the father (F). Positions of variants are indicated with arrowheads. B) A schematic picture of the exonintron structure of RARS2 and the domain structure of the encoded protein (modified from Gonzáles-Serrano et al., 2018) showing the locations of the identified mutations and high conservation of the leucine at position 321 affected by the missense substitution. C) Sanger sequencing chromatograms of the proband's cDNA showing only the paternal c.961C $>$ T variant (arrowhead) in exon 11 suggesting that the transcript derived from the maternal allele is degraded. $11 \mathrm{~F}$ denotes forward orientation sequence and $11 \mathrm{R}$ reverse orientation

Figure 3. Western blot, northern blot and aminoacylation analysis of the patient fibroblasts. 


\begin{abstract}
A) Steady-state level of mtArgRS protein in patient (P) and control fibroblasts ( $\mathrm{C} 1, \mathrm{C} 2)$ detected by
\end{abstract} Western blot. Quantification of the Western blot analysis is shown in the right panel. GAPDH was detected as protein loading control. Data are presented as mean \pm SD. B) Northern blot analysis of mt-tRNA ${ }^{\text {Arg }}$ levels in patient $(P)$ and control $(C 1, C 2)$ fibroblasts. Quantification of the northern blot analysis is shown in the lower panel. Mitochondrial tRNA ${ }^{\text {Ala }}$ was detected as a loading control.

C) Aminoacylation assay of mt-tRNA ${ }^{\text {Arg }}$ in control $(C 1, C 2)$ and patient $(P)$ fibroblasts. Mitochondrial tRNA ${ }^{\text {Ala }}$ was detected as a loading control. dAC denotes the fully deacylated control tRNA.

Experiments in B and C were carried out only once. 
Table 1. Overview of clinical features in published $\mathrm{PCH} 6$ patients

\section{CSF - cerebrospinal fluid}

${ }^{a}$ The features are variably reported in the patients.

Global developmental delay

$33 / 33$

Epileptic seizures

$24 / 24$

Microcephaly

$20 / 27$

MRI findings

Atrophy of cerebellum

$22 / 25$

Atrophy of pons

$12 / 25$

$18 / 25$

$19 / 23$

$10 / 19$

$17 / 18$

$6 / 8$ 


\section{References}

1067

10683

1069

$107 e^{44}$

1071

1073245

1073

107346

1075

107347

1077

107848

1079

108849

1081

108350

1083

108351

1085

108652

1087

108853

1089

109954

1091

109255

1094

10955

1096

109357

1098

109958

1100

110359

1102

110360

1104

110361

1106

110362

1108

110963

1110

111364

1112

111365

1114

111566

1116

$111 \overline{3} 67$

1118

1119

1120

1121

Alfadhel, M., Yong, S.L., Lillquist, Y., Langlois, S., 2011. Precocious puberty in two girls with PEHO syndrome: A clinical feature not previously described. J Child Neurol. 26(7):851-857. doi: 10.1177/0883073810396582.

Alkhateeb, A.M., Aburahma, S.K., Habbab, W., Thompson, I.R., 2016. Novel mutations in WWOX, RARS2, and C10orf2 genes in consanguineous arab families with intellectual disability. Metab Brain Dis. 31(4):901907. doi: 10.1007/s11011-016-9827-9.

Anttonen, A.-K., Hilander, T., Linnankivi, T., Isohanni, P., French, R.L., Liu, Y., Simonović, M., Söll, D., Somer, M., Muth-Pawlak, D., Corthals, G.L., Laari, A., Ylikallio, E., Lähde, M., Valanne, L., Lönnqvist, T., Pihko, H., Paetau, A., Lehesjoki, A.-E., Suomalainen, A., Tyynismaa, H., 2015. Selenoprotein biosynthesis defect causes progressive encephalopathy with elevated lactate. Neurology. 85(4):306-315. doi:

10.1212/WNL.0000000000001787.

Anttonen, A.-K., Laari, A., Kousi, M., Yang, Y.J., Jääskeläinen, T., Somer, M., Siintola, E., Jakkula, E., Muona, M., Tegelberg, S., Lönnqvist, T., Pihko, H., Valanne, L., Paetau, A., Lun, M.P., Hästbacka, J., Kopra, O., Joensuu, T., Katsanis, N., Lehtinen, M.K., Palvimo, J.J., Lehesjoki, A.-E., 2017. ZNHIT3 is defective in PEHO syndrome, a severe encephalopathy with cerebellar granule neuron loss. Brain. 140(5):1267-1279. doi: 10.1093/brain/awx040.

Caraballo, R.H., Pozo, A.N., Gomez, M., Semprino, M., 2011. PEHO syndrome: A study of five argentinian patients. Pediatr Neurol. 44(4):259-264. doi: 10.1016/j.pediatrneurol.2010.11.007.

Cassandrini, D., Cilio, M.R., Bianchi, M., Doimo, M., Balestri, M., Tessa, A., Rizza, T., Sartori, G., Meschini, M.C., Nesti, C., Tozzi, G., Petruzzella, V., Piemonte, F., Bisceglia, L., Bruno, C., Dionisi-Vici, C., D'Amico, A., Fattori, F., Carrozzo, R., Salviati, L., Santorelli, F.M., Bertini, E., 2013. Pontocerebellar hypoplasia type 6 
caused by mutations in RARS2: Definition of the clinical spectrum and molecular findings in five patients. $J$

Inherit Metab Dis. 36(1):43-53. doi: 10.1007/s10545-012-9487-9.

Chitre, M., Nahorski, M.S., Stouffer, K., Dunning-Davies, B., Houston, H., Wakeling, E.L., Brady, A.F., Zuberi, S.M., Suri, M., Parker, A.P.J., Woods, C.G., 2018. PEHO syndrome: The endpoint of different genetic epilepsies. J Med Genet. 55(12):803. doi: 10.1136/jmedgenet-2018-105288.

Chitty, L.S., Robb, S., Berry, C., Silver, D., Baraitser, M., 1996. PEHO or PEHO-like syndrome? Clin

Dysmorphol. 5(2):143-152.

Dong, J., Qiu, H., Garcia-Barrio, M., Anderson, J., Hinnebusch, A.G., 2000. Uncharged tRNA Activates GCN2 by Displacing the Protein Kinase Moiety from a Bipartite tRNA-Binding Domain. Molecular Cell. 6(2):269279. doi: 10.1016/S1097-2765(00)00028-9.

Edvardson, S., Shaag, A., Kolesnikova, O., Gomori, J.M., Tarassov, I., Einbinder, T., Saada, A., Elpeleg, O., 2007. Deleterious mutation in the mitochondrial arginyl-transfer RNA synthetase gene is associated with pontocerebellar hypoplasia. Am J Hum Genet. 81(4):857-862. doi: 10.1086/521227.

Field, M.J., Grattan-Smith, P., Piper, S.M., Thompson, E.M., Haan, E.A., Edwards, M., James, S., Wilkinson, I., Ades, L.C., 2003. PEHO and PEHO-like syndromes: Report of five australian cases. Am J Med Genet A. 122A(1):6-12. doi: 10.1002/ajmg.a.20216.

Flex, E., Niceta, M., Cecchetti, S., Thiffault, I., Au, M.G., Capuano, A., Piermarini, E., Ivanova, A.A., Francis, J.W., Chillemi, G., Chandramouli, B., Carpentieri, G., Haaxma, C.A., Ciolfi, A., Pizzi, S., Douglas, G.V., Levine, K., Sferra, A., Dentici, M.L., Pfundt, R.R., Le Pichon, J.-B., Farrow, E., Baas, F., Piemonte, F., Dallapiccola, B., Jr., G., John M., Saunders, C.J., Bertini, E., Kahn, R.A., Koolen, D.A., Tartaglia, M., 2016. Biallelic mutations in 
$T B C D$, encoding the tubulin folding cofactor $D$, perturb microtubule dynamics and cause early-onset

Gawlinski, P., Posmyk, R., Gambin, T., Sielicka, D., Chorazy, M., Nowakowska, B., Jhangiani, S.N., Muzny, D.M., Bekiesinska-Figatowska, M., Bal, J., Boerwinkle, E., Gibbs, R.A., Lupski, J.R., Wiszniewski, W., 2016.

PEHO syndrome may represent phenotypic expansion at the severe end of the early-onset

encephalopathies. Pediatr Neurol. 60:83-87.

Glamuzina, E., Brown, R., Hogarth, K., Saunders, D., Russell-Eggitt, I., Pitt, M., de Sousa, C., Rahman, S., Brown, G., Grunewald, S., 2012. Further delineation of pontocerebellar hypoplasia type 6 due to mutations in the gene encoding mitochondrial arginyl-tRNA synthetase, RARS2. J Inherit Metab Dis. 35(3):459-467.

González-Serrano, L.E., Karim, L., Pierre, F., Schwenzer, H., Rötig, A., Munnich, A., Sissler, M., 2018. Three human aminoacyl-tRNA synthetases have distinct sub-mitochondrial localizations that are unaffected by disease-associated mutations. J Biol Chem. 293(35):13604-13615. doi: 10.1074/jbc.RA118.003400.

Haltia M, Somer M. 1993. Infantile cerebello-optic atrophy. Neuropathology of the progressive encephalopathy syndrome with edema, hypsarrhythmia and optic atrophy (the PEHO syndrome). Acta Neuropathol. 85(3):241-247.

Ibba M, Soll D., 2000. Aminoacyl-tRNA synthesis. Annu Rev Biochem. 69:617-650. doi:

10.1146/annurev.biochem.69.1.617.

Joseph, J.T., Innes, A.M., Smith, A.C., Vanstone, M.R., Schwartzentruber, J.A., Bulman, D.E., Majewski, J., Daza, R.A., Hevner, R.F., Michaud, J., Boycott, K.M., Consortium, F.C., 2014. Neuropathologic features of 
pontocerebellar hypoplasia type 6. J Neuropathol Exp Neurol. 73(11):1009-1025. doi:

10.1097/NEN.0000000000000123.

Kastrissianakis, K., Anand, G., Quaghebeur, G., Price, S., Prabhakar, P., Marinova, J., Brown, G., McShane, T., 2013. Subdural effusions and lack of early pontocerebellar hypoplasia in siblings with RARS2 mutations.

Arch Dis Child. 98(12):1004-1007. doi: 10.1136/archdischild-2013-304308.

Konovalova S, Tyynismaa H., 2013. Mitochondrial aminoacyl-tRNA synthetases in human disease. Mol Genet Metab. 108(4):206-211. doi: 10.1016/j.ymgme.2013.01.010.

Langlois, S., Tarailo-Graovac, M., Sayson, B., Drogemoller, B., Swenerton, A., Ross, C.J., Wasserman, W.W., van Karnebeek, C.D., 2016. De novo dominant variants affecting the motor domain of KIF1A are a cause of PEHO syndrome. Eur J Hum Genet. 24(6):949-953. doi: 10.1038/ejhg.2015.217.

Lax, N.Z., Alston, C.L., Schon, K., Park, S.M., Krishnakumar, D., He, L., Falkous, G., Ogilvy-Stuart, A., Lees, C., King, R.H., Hargreaves, I.P., Brown, G.K., McFarland, R., Dean, A.F., Taylor, R.W., 2015. Neuropathologic characterization of pontocerebellar hypoplasia type 6 associated with cardiomyopathy and hydrops fetalis and severe multisystem respiratory chain deficiency due to novel RARS2 mutations. J Neuropathol Exp Neurol. 74(7):688-703. doi: 10.1097/NEN.0000000000000209

Lek, M., Karczewski, K.J., Minikel, E.V., Samocha, K.E., Banks, E., Fennell, T., O’Donnell-Luria, A.H., Ware, J.S., Hill, A.J., Cummings, B.B., Tukiainen, T., Birnbaum, D.P., Kosmicki, J.A., Duncan, L.E., Estrada, K., Zhao, F., Zou, J., Pierce-Hoffman, E., Berghout, J., Cooper, D.N., Deflaux, N., DePristo, M., Do, R., Flannick, J., Fromer, M., Gauthier, L., Goldstein, J., Gupta, N., Howrigan, D., Kiezun, A., Kurki, M.I., Moonshine, A.L., Natarajan, P., Orozco, L., Peloso, G.M., Poplin, R., Rivas, M.A., Ruano-Rubio, V., Rose, S.A., Ruderfer, D.M., Shakir, K., Stenson, P.D., Stevens, C., Thomas, B.P., Tiao, G., Tusie-Luna, M.T., Weisburd, B., Won, H.H., Yu, D., Altshuler, D.M., Ardissino, D., Boehnke, M., Danesh, J., Donnelly, S., Elosua, R., Florez, J.C., Gabriel, S.B., 
Getz, G., Glatt, S.J., Hultman, C.M., Kathiresan, S., Laakso, M., McCarroll, S., McCarthy, M.I., McGovern, D., 130346

McPherson, R., Neale, B.M., Palotie, A., Purcell, S.M., Saleheen, D., Scharf, J.M., Sklar, P., Sullivan, P.F.,

Tuomilehto, J., Tsuang, M.T., Watkins, H.C., Wilson, J.G., Daly, M.J., MacArthur, D.G., Consortium, E.A., 2016. Analysis of protein-coding genetic variation in 60,706 humans. Nature. 536(7616):285-291. doi:

Li, H., Handsaker, B., Wysoker, A., Fennell, T., Ruan, J., Homer, N., Marth, G., Abecasis, G., Durbin, R.,

Subgroup, 1000 Genome Project Data Processing, 2009. The sequence alignment/map format and SAMtools. Bioinformatics. 25(16):2078-2079. doi: 10.1093/bioinformatics/btp352.

Li, Z., Schonberg, R., Guidugli, L., Johnson, A.K., Arnovitz, S., Yang, S., Scafidi, J., Summar, M.L., Vezina, G., Das, S., Chapman, K., del Gaudio, D., 2015. A novel mutation in the promoter of RARS2 causes pontocerebellar hypoplasia in two siblings. J Hum Genet. 60(7):363-369. doi: 10.1038/jhg.2015.31.

Longman, C., Tolmie, J., McWilliam, R., MacLennan, A., 2003. Cranial magnetic resonance imaging mistakenly suggests prenatal ischaemia in PEHO-like syndrome. Clin Dysmorphol. 12(2):133-136. doi: 10.1097/01.mcd.0000059769.40218.d2.

Luhl, S., Bode, H., Schlotzer, W., Bartsakoulia, M., Horvath, R., Abicht, A., Stenzel, M., Kirschner, J., Grunert, S.C., 2016. Novel homozygous RARS2 mutation in two siblings without pontocerebellar hypoplasia - further expansion of the phenotypic spectrum. Orphanet J Rare Dis. 11(1):9. doi: 10.1186/s13023-016-0525-9.

Miyake, N., Fukai, R., Ohba, C., Chihara, T., Miura, M., Shimizu, H., Kakita, A., Imagawa, E., Shiina, M., Ogata, K., Okuno-Yuguchi, J., Fueki, N., Ogiso, Y., Suzumura, H., Watabe, Y., Imataka, G., Leong, H.Y., Fattal-

Valevski, A., Kramer, U., Miyatake, S., Kato, M., Okamoto, N., Sato, Y., Mitsuhashi, S., Nishino, I., Kaneko, N., Nishiyama, A., Tamura, T., Mizuguchi, T., Nakashima, M., Tanaka, F., Saitsu, H., Matsumoto, N., 2016. 
Biallelic TBCD mutations cause early-onset neurodegenerative encephalopathy. Am J Hum Genet.

Namavar, Y., Barth, P.G., Kasher, P.R., van Ruissen, F., Brockmann, K., Bernert, G., Writzl, K., Ventura, K.,

Nahorski, M.S., Asai, M., Wakeling, E., Parker, A., Asai, N., Canham, N., Holder, S.E., Chen, Y.C., Dyer, J., Brady, A.F., Takahashi, M., Woods, C.G., 2016. CCDC88A mutations cause PEHO-like syndrome in humans and mouse. Brain. 139(4):1036-1044. doi: 10.1093/brain/aww014.

Cheng, E.Y., Ferriero, D.M., Basel-Vanagaite, L., Eggens, V.R., Krageloh-Mann, I., De Meirleir, L., King, M., Graham, J.M., Jr, von Moers, A., Knoers, N., Sztriha, L., Korinthenberg, R., Consortium, P., Dobyns, W.B., Baas, F., Poll-The, B.T., 2011. Clinical, neuroradiological and genetic findings in pontocerebellar hypoplasia. Brain. 134(1):143-156. doi: 10.1093/brain/awq287.

Ngoh, A., Bras, J., Guerreiro, R., Meyer, E., McTague, A., Dawson, E., Mankad, K., Gunny, R., Clayton, P., Mills, P.B., Thornton, R., Lai, M., Forsyth, R., Kurian, M.A., 2016. RARS2 mutations in a sibship with infantile spasms. Epilepsia. 57(5):e97-102. doi: 10.1111/epi.13358.

Nishri, D., Goldberg-Stern, H., Noyman, I., Blumkin, L., Kivity, S., Saitsu, H., Nakashima, M., Matsumoto, N., Leshinsky-Silver, E., Lerman-Sagie, T., Lev, D., 2016. RARS2 mutations cause early onset epileptic encephalopathy without ponto-cerebellar hypoplasia. Eur J Paediatr Neurol. 20(3):412-417. doi:

10.1016/j.ejpn.2016.02.012.

Õunap, K., Muru, K., Õiglane-Shlik, E., Ilves, P., Pajusalu, S., Kuus, I., Wojcik, M.H., Reimand, T., 2019. PEHO syndrome caused by compound heterozygote variants in ZNHIT3 gene. European Journal of Medical Genetics. . doi: 10.1016/j.ejmg.2019.04.017. 
Rankin, J., Brown, R., Dobyns, W.B., Harington, J., Patel, J., Quinn, M., Brown, G., 2010. Pontocerebellar

hypoplasia type 6: A british case with PEHO-like features. Am J Med Genet A. 152A(8):2079-2084. doi:

10.1002/ajmg.a.33531

Rausch, T., Zichner, T., Schlattl, A., Stütz, A.M., Benes, V., Korbel, J.O., 2012. DELLY: Structural variant discovery by integrated paired-end and split-read analysis. Bioinformatics. 28(18):i339. doi:

10.1093/bioinformatics/bts378.

Salonen, R., Somer, M., Haltia, M., Lorentz, M., Norio, R., 1991. Progressive encephalopathy with edema, hypsarrhythmia, and optic atrophy (PEHO syndrome). Clin Genet. 39(4):287-293.

Somer M., 1993. Diagnostic criteria and genetics of the PEHO syndrome. J Med Genet. 30(11):932-936.

Sulonen, A.M., Ellonen, P., Almusa, H., Lepisto, M., Eldfors, S., Hannula, S., Miettinen, T., Tyynismaa, H., Salo, P., Heckman, C., Joensuu, H., Raivio, T., Suomalainen, A., Saarela, J., 2011. Comparison of solutionbased exome capture methods for next generation sequencing. Genome Biol. 12(9):r94. Doi: 10.1186/gb2011-12-9-r94.

van Dijk, T., van Ruissen, F., Jaeger, B., Rodenburg, R.J., Tamminga, S., van Maarle, M., Baas, F., Wolf, N.I., Poll-The, B.T., 2017. RARS2 mutations: Is pontocerebellar hypoplasia type 6 a mitochondrial encephalopathy? JIMD Rep. 33:87-92. doi: 10.1007/8904_2016_584.

van Dijk, T., Baas, F., Barth, P.G., Poll-The, B.T., 2018. What's new in pontocerebellar hypoplasia? an update on genes and subtypes. Orphanet journal of rare diseases. 13(1). doi: 10.1186/s13023-018-0826-2.

Wang K, Li M, Hakonarson H., 2010. ANNOVAR: Functional annotation of genetic variants from highthroughput sequencing data. Nucleic Acids Res. 38(16):e164. doi: 10.1186/s13023-018-0826-2 
Wolfson, R.L., Chantranupong, L., Saxton, R.A., Shen, K., Scaria, S.M., Cantor, J.R., Sabatini, D.M., 2016.

Sestrin2 is a leucine sensor for the mTORC1 pathway. Science. 351(6268):43-48. doi:

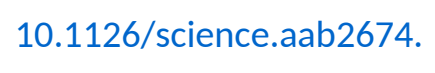

Zhang, J., Zhang, Z., Zhang, Y., Wu, Y., 2018. Distinct magnetic resonance imaging features in a patient with novel RARS2 mutations: A case report and review of the literature. Exp Ther Med. 15(1):1099-1104. doi: 10.3892/etm.2017.5491.

Zollo, M., Ahmed, M., Ferrucci, V., Salpietro, V., Asadzadeh, F., Carotenuto, M., Maroofian, R., Al-Amri, A., Singh, R., Scognamiglio, I., Mojarrad, M., Musella, L., Duilio, A., Di Somma, A., Karaca, E., Rajab, A., AlKhayat, A., Mohan Mohapatra, T., Eslahi, A., Ashrafzadeh, F., Rawlins, L.E., Prasad, R., Gupta, R., Kumari, P., Srivastava, M., Cozzolino, F., Kumar Rai, S., Monti, M., Harlalka, G.V., Simpson, M.A., Rich, P., Al-Salmi, F., Patton, M.A., Chioza, B.A., Efthymiou, S., Granata, F., Di Rosa, G., Wiethoff, S., Borgione, E., Scuderi, C., Mankad, K., Hanna, M.G., Pucci, P., Houlden, H., Lupski, J.R., Crosby, A.H., Baple, E.L., 2017. PRUNE is crucial for normal brain development and mutated in microcephaly with neurodevelopmental impairment. Brain. 
Supplemental Data

Supplementary Table: Phenotypic features in published PCH6 patients 


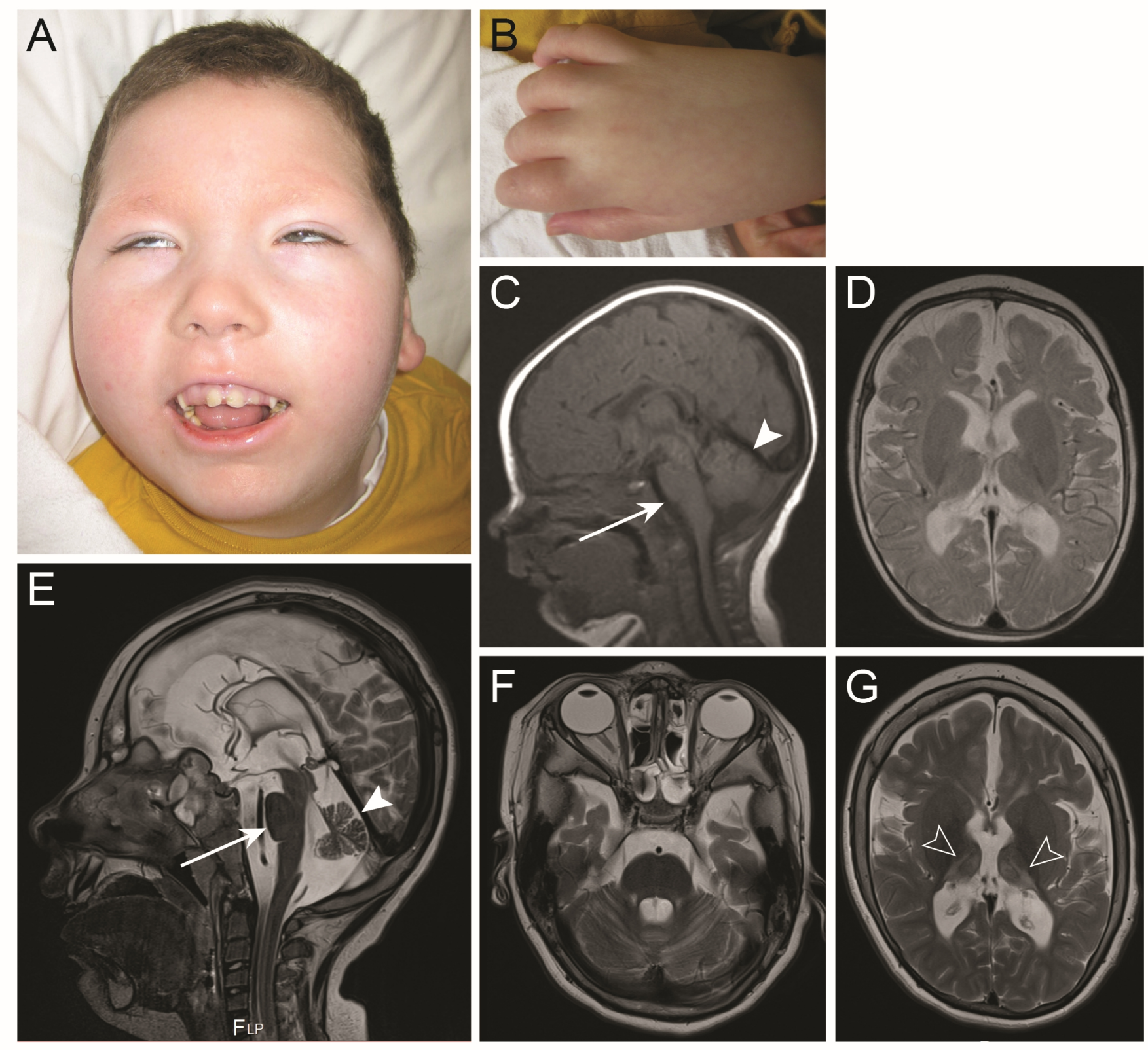


A

c.795delA

p.Glu265Aspfs*16

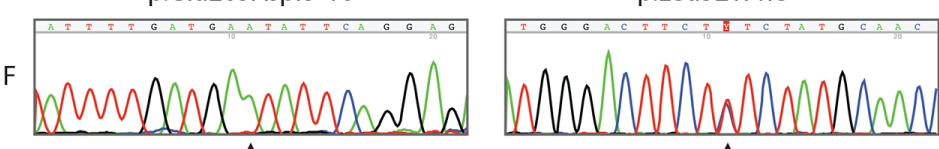

M

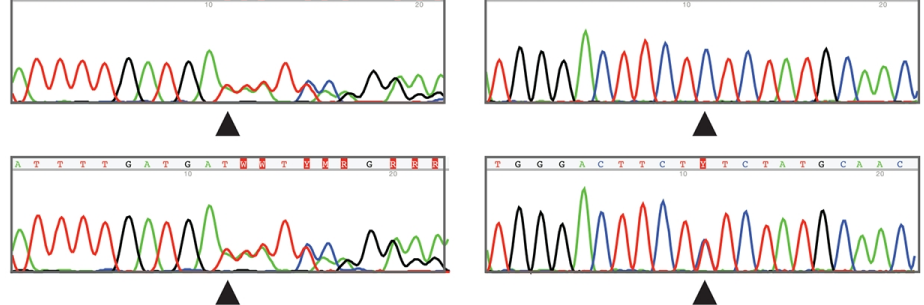

$11 \mathrm{~F}$

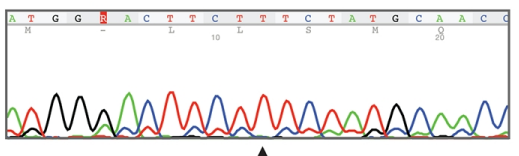

$11 R$

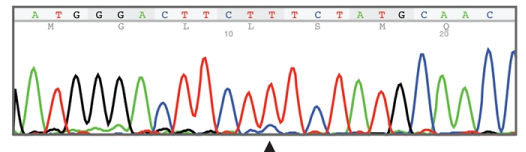

B

RARS2

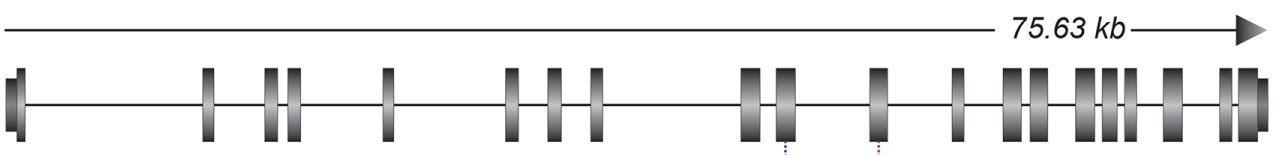

p.Glu265Aspfs*16 p.Leu321Phe

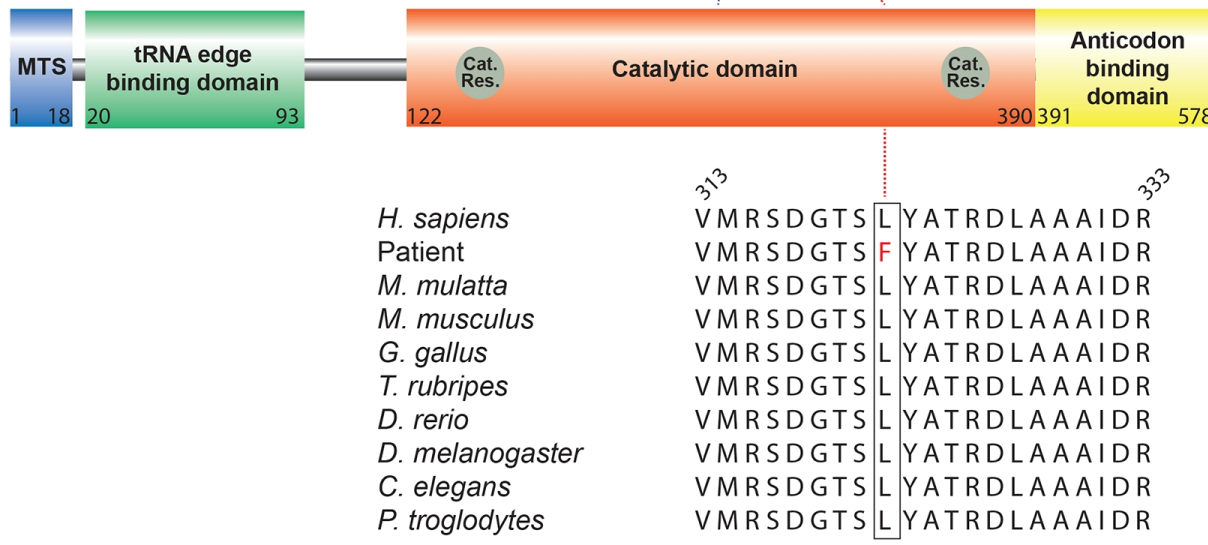



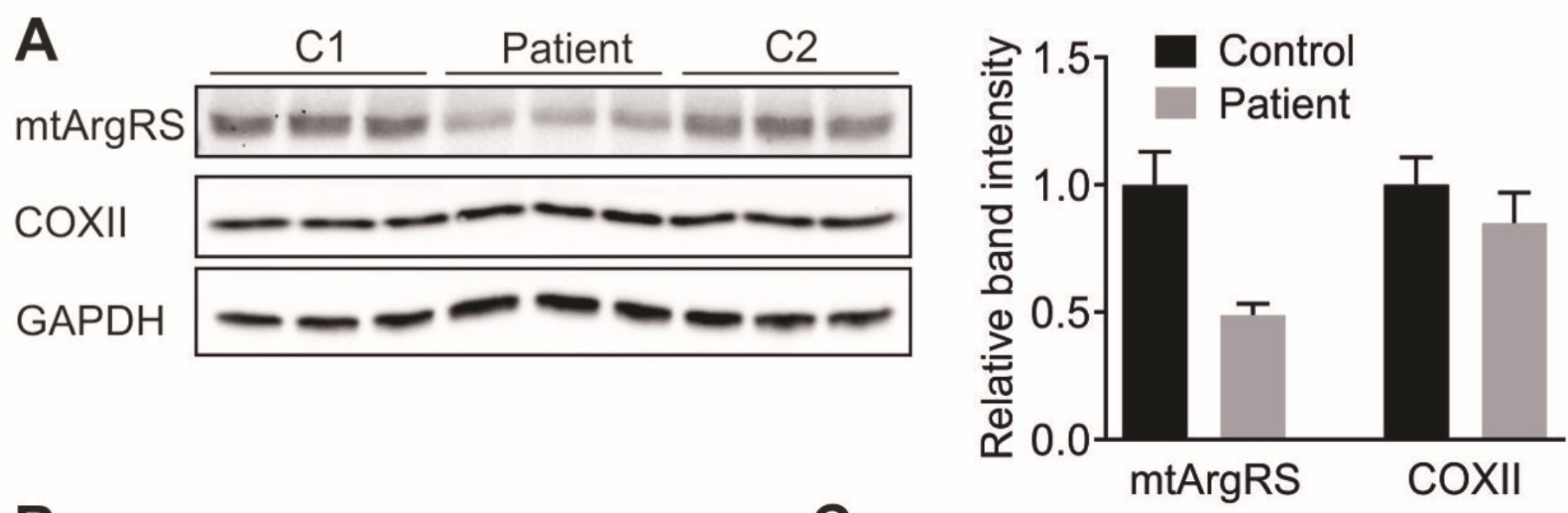

B

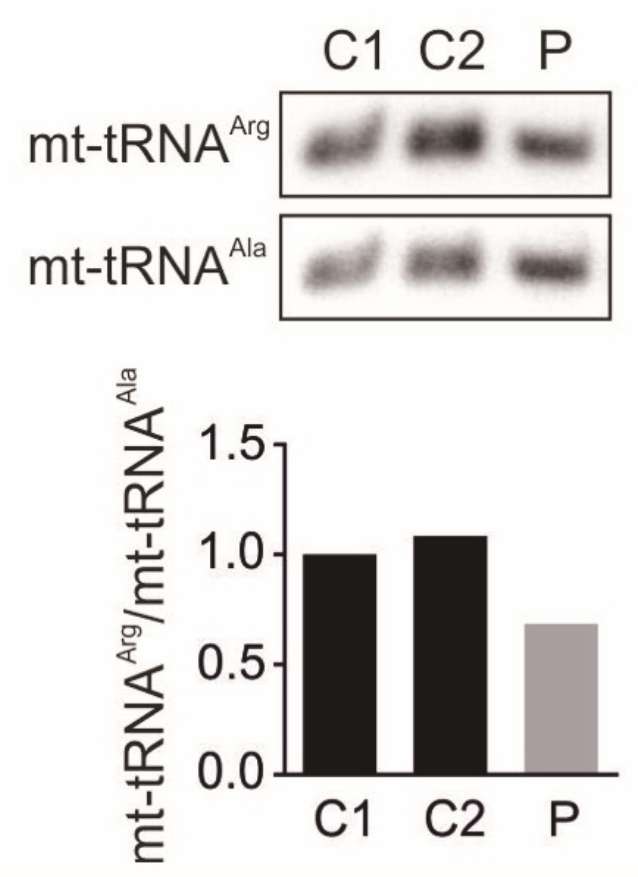

C

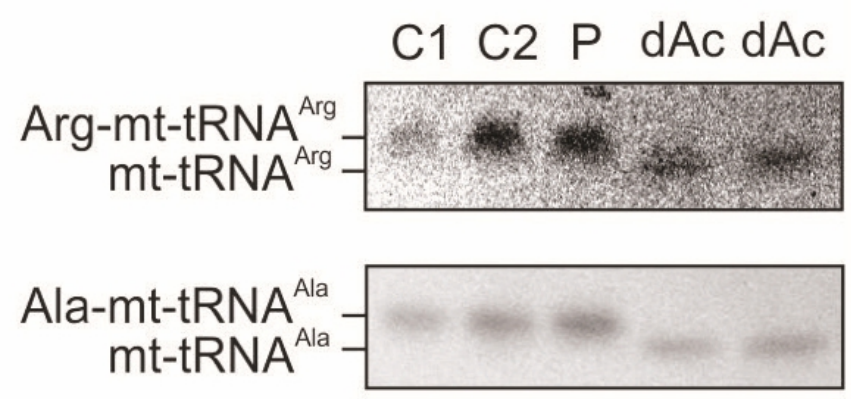


Table 1. Overview of clinical features in $\mathrm{PCH} 6$ patients

\begin{tabular}{ll}
\hline Feature & $\mathbf{n} / \mathbf{n}^{\mathbf{a}}$ \\
\hline Global developmental delay & $33 / 33$ \\
Epileptic seizures & $24 / 24$ \\
Microcephaly & $20 / 27$ \\
MRI findings & \\
$\quad$ Atrophy of cerebellum & $22 / 25$ \\
$\quad$ Atrophy of pons & $12 / 25$ \\
$\quad$ Atrophy of cerebrum & $18 / 25$ \\
Elevated lactate level in blood or CSF & $19 / 23$ \\
Reduced respiratory chain enzyme activity & $10 / 19$ \\
Feeding difficulties & $17 / 18$ \\
Dysmorphic features & $6 / 8$
\end{tabular}

CSF - cerebrospinal fluid

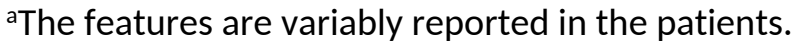


The first author of the manuscript and the corresponding author (if different) certify on honor, on behalf of all co-authors, that they have been granted a permission to publish signed by the patient himself (or by his legal representatives) for each patient whose facial features are identifiable in the photographs illustrating this article. The authors maintain in their files a copy of this consent, which will be forwarded to Elsevier in case of complaints or legal proceedings.

Figures for which a signed consent has been obtained:

\begin{tabular}{|c|l|l|l|}
\hline Figure number & Figure number & Figure number & Figure number \\
\hline FIGURE 1 & & & \\
\hline & & & \\
\hline & & & \\
\hline
\end{tabular}

\begin{tabular}{|l|l|l|}
\hline [Signature of corresponding author redacted] & $\begin{array}{c}\text { Name } \\
\text { LEHESJOKI }\end{array}$ & $\begin{array}{c}\text { Forename } \\
\text { ANNA-ELINA }\end{array}$ \\
\hline
\end{tabular}

